\title{
Building Walkways: Observation on Nest Duplication of Stingless Bee Trigona iridipennins Smith (1854)
}

\author{
Preeti S. Virkar*, Shivam Shrotriya \& \\ V. P. Uniyal \\ Wildlife Institute of India, Po. Box. 18, Chandrabani, \\ Dehradun 248001 (Uttarakhand, India)
}

Study Area: Dehradun, Uttarakhand, India Coordinates: $30^{\circ} 17^{\prime} 2.24^{\prime \prime N}, 77^{\circ} 58^{\prime} 30.48^{\prime \prime} \mathrm{E}$

Key words: Nesting habits, Stingless Bees, Trigona iridipennins

\section{Introduction}

Beekeeping for honey and other bee products is an age old practice. Besides the popular honeybees, Apis cerana and Apis mellifera, stingless bees belonging to the tribe Meliponini, subfamily Apinae and family Apidae (Michener, 2007) are also reared for honey, having high medicinal value. Stingless bees are exclusive to tropics and their size ranges from $2 \mathrm{~mm}$ to slightly bigger than the popular honeybee $A$. mellifera (O'Toole \& Raw, 1999). The practice of keeping stingless bees is called meliponiculture, and once it was an integral part of the culture of indigenous people of South and Central America. It held a social and religious significance in the meso-American culture, mainly the ancient Mayans (Sommeijer, 1999). Stingless bee products such as honey, wax and propolis formed a small-scale economy in their livelihood as well (Cortopassi-Laurino et al., 2006). Although least explored, meliponiculture is an age old practice in India also. Kani tribe in Western Ghats is the only reported reference, keeping stingless bees (Kumar et al., 2012). Trigona iridipennis is the widespread stingless bee species in the Indian subcontinent and used for meliponiculture.

Stingless bees nest in a variety of habitats ranging from cracks, crevices of trees, walls and sometimes even underground. Some species may construct exposed nests on tree trunks, walls or cliff faces. The nests are built using wax, secreted from the metastomal terga, mixed with plant resins and gums. Certain species build different portions of nest with particular materials such as mud, faeces etc. (Rasmussen \& Camargo, 2008). These nests are enclosed in batumen, a black waxy bee product which is also used to fill in unused spaces. The nest has different chambers for brood (queen and larvae), honey and pollen pots largely made from wax making them soft, which are separated by an involucrum (Barbosa et al., 2013; Michener, 2007; O'Toole \& Raw, 1999). However, T. iridipennis colonizes cavities in trees, walls etc. (Danareddi et al.,

*Corresponding Author: preeti@wii.gov.in 

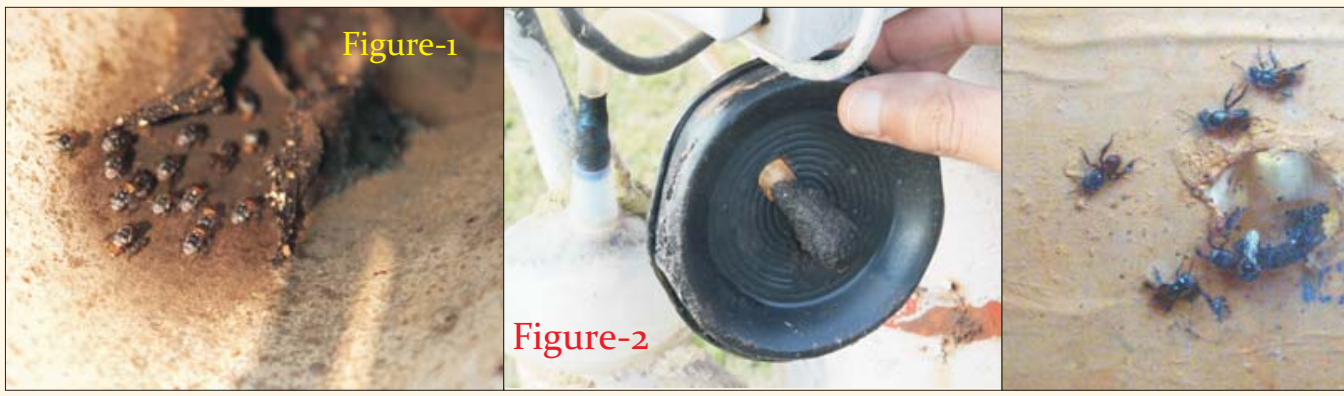

Figure-3

Fig.-1: Entrance of the nest of T.iridipennis; Fig.-2: Batumen extension joining the original entrance to the new one through the earthn urn. Fig.-3 Building structure in wooden nest box.

2007), but their specific nesting habits are not yet well studied.

Collection of honey and other bee products from natural nests of stingless bees is destructive and threatens their survival. Thus, meliponiculture has been suggested to adopt, benef itting both stingless bees and local communities (Oliveira et al., 2012; CortopassiLaurino et al., 2006). Stingless bees are acquired from their colonies in the wild for rearing. 'Hiving' and 'Eduction' are the two existing methods of acquiring stingless bee colonies. Hiving is a commonly used method, where naturally occurring colonies are transferred into bee boxes (Heard, 1988). Although this process is expeditious, transferring them from their natural habitat is destructive to the original colonies. Alternatively in the eduction method, an artif icial nesting cavity (box) is attached to the entrance of the original colony, which gradually grows and divides. Though the process doesn't damage the nest, it can take from a few months to over a year to divide (Vijayakumar et al., 2012; Klumpp, 2007; Dollin, 2001). Uncertainty of time/duration for nest duplication in stingless bees is a major setback for the proper application of education in meliponiculture. Space requirement for the new colony and materials used to build the nest vary for different species and could play important role in decision to split the nest (Oliviera et al., 2012; Crane, 1999; Murillo, 1984). We report the initial observations on the study of eduction process in stingless bees and factors affecting the same.

We found three nests of $T$. iridipennis within the campus of Wildlife Institute of India, Dehradun, Uttarakhand, India (30 $\left.17^{\prime} 2.24^{\prime \prime} \mathrm{N}, 77^{\circ} 5^{\prime} 30.48^{\prime \prime E}\right)$, in July 2013. All the nests were built in artif icial structures, two in horizontal water run-off pipes and one in a vertical opening of earthing system at the base of lamp-post (Fig. 1). To initiate eduction, we attached earthen urns of 0.9 litre capacity with two of the nests, leaving the possible entry/exit only through the urns. Interestinlgly, the bees did not use the provided space for extending or duplicating the original hive. Instead a tubular structure was built in both the instances, joining the original entrances to the new ones through the urns. The structure was made of bee batumen, which supports the hive structure and is used to seal the excess openings (O'Toole \& Raw, 1999). The major materials used were wax, mud and wastes (bee pellets) from nest, which were visible to naked eyes. These were closely bound with shiny resin to form the extensions (Fig. 2). We hypothesize three possible reasons that could impede eduction in the provided setup. Space limitations might potentially discourage nest splitting. Nest-box material, i.e., earthen urn, 
could be avoided due to possible moisture retention. Constructing extensions for directed movement in the dark is cost effective and energy efficient over nest propagation during resource constrain period. Second hypothesis, however, could be ruled out by closer observation of the structure of extensions. Holding the structure against light showed small pores/vents, presumably for air passage. Such structures may not be constructed to avoid moisture. In absence of enough data to support, we cannot establish whether single or multiple factors trigger nest splitting in T. iridipennis. In mid-November 2013, we replaced one urn with wooden box of 2 litres capacity and the third nest was also attached with similar wooden box. Both of these colonies have initiated building structures in wooden boxes (Fig. 3). Further experiment is in progress to gather more data for conclusive results. We expect that the outcome of this study will add information to stingless bee ecology and meliponiculture. Understanding specif ic nesting habits can make eduction technique eff icient and adaptable to beekeepers.

\section{References:}

Barbosa F.M., de Oliveira Alves R.M., de Almeida Sauza B., \& Lopes de Carvalho C.A. (2013): Nest architecture of the stingless bee Geotrigona subterranea (Friese, 1901) (Hymenoptera: Apidae: Meliponini). Biota Neotropica, 13(1);147-152.

Cortopassi-Laurino M., Imperatriz-Fonseca V.L., Roubik D.W., Dollin A., Heard T., Aguilar I.B., Venturieri G.C., Eardley C. \& Nogueira-Neto P. (2006): Global Meliponiculture: challenges and opportunities. Apidologie, 37: 118.

Crane E. (1999): The World History of Beekeeping and Honey Hunting. 682 pp. Publisher: Routledge, New York.

Danareddi C.S. (2007): Studies on Stingless bee, Trigona iridipennis Smith with special reference to foraging behaviour and melissopalynology at Dharwad, Karnataka. M.Sc. Thesis. University of Agricultural Sciences, Dharwad.

Dollin A. (2001): Natural Hive Duplication: An Alternative Method of Propagating Australian Stingless Bees. Aussie Bee Online. Article3, November 2001 (http://www.aussiebee.com.au/aussiebeeonlineoo3.pdf).

Heard T.A. (1988): Propagation of Hives of Trigona carbonaria Smith. J.Aust. Entomol. Soc., 27;303-304.

Klumpp J.D. (2007): Australian Stingless Bees: A Guide to Sugarbag Beekeeping. Publisher: Earthling Enterprises.

Kumar M.S., Singh A.J.A.R. \& Alagumuthu G. (2012): Traditional beekeeping of stingless bees (Trigona sp.) by Kani tribes of Western Ghats, Tamil Nadu, India. Indian Journal of Traditional Knowledge, 11:342-345.

Michener C.D. (2007): The Bees of the World. 2nd Edn. Publisher: John Hopkins University Press, Baltimore, Maryland.

Murillo R.M. (1984): Uso y manejo actual de lascolonies de Melipona beecheii Bennett (Apidae: Meliponini) en el estado de Tabasco, Mexico. Biotica, 9:423-428.

Oliveira R.C., Menezes C., Soares A.E.E. \& Fonseca V.L.I. (2012): Trap-nests for stingless bees (Hymenoptera, Meliponini). Apidologie, 44(1):29-37.

O'Toole C. \& Raw A. (1999): Bees of the World. Publisher: Facts on File.

Rasmussen C. \& Camargo J.M.F. (2008): A molecular phylogeny and evolution of nest architecture and behaviour in Trigona sp. (Hymenoptera:Apidae: Meliponini). Apidologie, 39:120-118.

Sommeijer M.J. (1999): Beekeeping with stingless bees: a new type of hive. Bee World, 8o(2); 70-79.

Vijayakumar K., Muthuraman M. \& Jayaraj R. (2013): Propagating Trigona iridipennis Colonies (Apidae: Meliponini) By Eduction Method. Scholars Academic Journal of Biosciences, 1(1): 1-3. 